\title{
Design é coisa de veado: estratégias para o desenho de uma plataforma digital para memórias sexo e gênero dissidentes.
}

\section{Design is a faggot thing: strategies for the design of a digital platform for gender and sex dissidents memories.}

\author{
Guilherme Altmayer, ESDI/UERJ. \\ galtmayer@esdi.uerj.br \\ Leno Veras, ECO/UFRJ. \\ verasleno@gmail.com
}

\section{Resumo}

Articulando reflexões teóricas queer, com Michel Foucault, Judith Butler, e Paul B. Preciado, e sobre arquivo com Achiles Mbembe e Jack Halberstam, no presente texto objetivamos analisar o papel do design como meio que dá forma a discursos, questionando epistemologicamente suas estruturas normativas e alertando para as responsabilidades éticas imbricadas no planejamento e execução de uma plataforma digital para salvaguarda de múltiplas narrativas de corpos e manifestações estético-políticas bixas, sapas, lésbicas, trans e travestis: tropicuir.org. Um percurso transdisciplinar que investiga possibilidades de uma queerização, ou estranhamento do Design para dar a ver algumas implicações políticas e responsabilidades éticas do campo, ao mesmo tempo que articula meios para configuração de espaços livres de censura e ferramentas para auto representação como estratégias de sobrevivência de muitas memórias transviadas sistematicamente apagadas.

Palavras-chave: design político, gênero e sexualidade, políticas de memória

\begin{abstract}
Articulating queer theoretical reflections, with Michel Foucault, Judith Butler, and Paul B. Preciado, and on archiving with Achiles Mbembe and Jack Halberstam, in this article we aim to analyze the role of design as a means of shaping discourses, epistemologically questioning its normative structures and warning about the ethical responsibilities embedded in the planning and execution of a platform that encompasses multiple narratives of faggots, dykes, lesbians, and trans bodies and their aesthetic-political manifestations: tropicuir.org. A transdisciplinar route that investigates design queerying possibilities in order to reveal some political implications and ethical responsibilities of the field and at the same time articulates means of configuration of spaces free from censorship, as well as tools for self representation as strategies of survival to so many queer memories that are systematically erased.
\end{abstract}

Keywords: political design, gender and sexuality, politics of memory 


\section{Introdução}

A partir de experiências no desenho e implementação uma plataforma digital - tropicuir.org destinada à salvaguarda e comunicação de memórias estético-políticas de pessoas sexo e gênero dissidentes no Brasil, propomos, no presente texto, investigar possibilidades de uma abordagem queerizada do campo do Design. Navegando pela teoria queer e alguns pensadores críticos de práticas arquivísticas, propomos lançar um olhar transdisciplinar sobre o Design como um lugar de práxis política, produtor de discursos, questionando suas estruturas normativas e alertando para responsabilidades éticas imbricadas para dar conta da diversidade de narrativas e formas de corpos transviados que fazem parte do projeto.

O termo "transviado" frequentemente mencionado nesta escrita, é trazido da pesquisadora Berenice Bento (2015) para designar estudos/ativismos transviados - se aproxima do significado do termo "queer", uma tradução considerada pertinente pela autora para pensar em um termo "guarda-chuva" para ações sexo e gênero dissidentes e reflexões teóricas a partir do sul global. No dicionário Dicio ${ }^{1}$, o termo transviado significa: "aquele que se transviou; quem se afastou dos bons costumes; desencaminhado; que se perdeu do caminho; que se opõe aos padrões comportamentais preestabelecidos ou vigentes".

Tropicuir.org consiste na materialização de uma plataforma de memórias, visibilidades e manifestações transviadas, construída através de uma série de ações de curadoria artística praticadas em interação com coletivos ligados a movimentos sociais e artísticos, transcorridas principalmente entre 2013 e 2019 na cidade do Rio de Janeiro. A plataforma objetiva refletir sobre a intercomunicação e potencialização entre os campos da Arte e Design, os ativismos políticos, as ruas e a academia para dar a ver as formas como estes eventos e corpos se interconectam e comunicam redes de resistências contra normativas de sexualidade e gênero a partir de práticas estéticas. E para além, propor práticas e exercícios de rememoração e modos de arquivar juntas esses acontecimentos, visando sua inscrição na história das artes, dos ativismos e das políticas transviadas.

O nome tropicuir deriva da junção de dois termos: tropi + cuir, e é inspirado no título do manuscrito Mario Montez: Tropicamp do artista Hélio Oiticica. "Tropi” deriva de tropical, e remete à construção dos imaginários alegóricos dos trópicos brasileiros como um paraíso, alegorias criadas pela ditadura militar (1964-1985), como processo de esvaziamento da cena musical de seus elementos críticos - traço característico no início do movimento da Tropicália. Já cuir é uma tradução propositalmente malfeita de queer - um olhar crítico à inteligibilidade queer desde o sul latino-americano. Uma forma de escrita acionada pelo artista chileno Felipe Rivas na performance em vídeo "Diga 'queer' con la lengua afuera"2 ${ }^{2}$ na qual tenta pronunciar a palavra queer com a língua de fora.

O caminho apresentado para esta escrita passa por uma breve introdução aos estudos de gênero e sexualidade, ou estudos queer, e suas propostas teóricas e práticas contra normativas, enquanto

\footnotetext{
${ }^{1}$ Ver https://www.dicio.com.br/transviado/

${ }^{2}$ Ver http://www.feliperivas.com/diga-queer-con-la-lengua-afuera.html
} 
vertente de pesquisa que subsidia o pensar crítico sobre as condições que tornaram gênero e sexualidade campos centrais de disputa política nas sociedades ocidentalizadas. Arcabouço teórico do qual lançaremos mão para debruçarmo-nos então, em um segundo momento, sobre exercícios arquivísticos na construção da plataforma de salvaguarda, entendendo o papel do design como meio, dispositivo que opera discursos e projeta formas; corresponsável pela visibilidade e conformação discursiva.

Frente ao entendimento de que o designer pode ser corresponsável pelos ditos, e não ditos, que constituem discursos normativos, podemos recorrer à filósofa Donna Haraway (1995) em Saberes Localizados: a questão da ciência para o feminismo e o privilégio da perspectiva parcial, para evidenciar que uma proposta epistemológica de saber situado é uma ação política que reconhece que a produção de conhecimento não está descontextualizada, tampouco desligada, da subjetividade de quem a realiza.

Relatar o ponto de onde partimos é atestar que não existe neutralidade no fazer design. É, sobretudo, entender a importância de uma constante reavaliação crítica das próprias práticas, e táticas, de ver. Até porque, segundo a autora, a visão é sempre uma questão do poder de ver e de uma violência implícita em nossas práticas de visualização: "com o sangue de quem foram feitos meus olhos?" (HARAWAY, 1995, p. 25), questiona a filósofa.

A essa pergunta, podemos agregar muitas outras, derivadas das relações de poder nas quais fazemos parte: de que forma e a partir de onde é possível ver? Qual a amplitude do campo visual? Quais outros sentidos estamos usando além da visão? O que não estamos enxergando? Dar a ver o viés político do designer e suas práticas trata-se de, não apenas questionar um campo que evita lançar um olhar crítico sobre si mesmo, mas também criar possibilidades de construção de métodos, técnicas e processos mais coletivizados e localizados.

Cabe, segundo essa proposição ao campo de conhecimento do Design, compreender seu caráter transdisciplinar, naturalmente indisciplinado, que não vê limitações entre sua origem na teoria social e sua atuação na inovação tecnológica; mas, ao revés, entender-se como área do saber que tem implicações culturais, econômicas, políticas e sociais enquanto maneira de fazer.

Derivado do latim designare, o design pode também ser entendido não somente como desenho e plano esquemático para alcançar um fim, mas também como uma ação que designa, que determina, que implica estruturas que servem de suporte aos registros de memórias de praticas sexo e gênero dissidentes. É preciso portanto desmunhecar e enviadescer o fazer design para criar estratégias de queerização do campo que envolvem não somente buscar uma "desheteronormatização" de seus alicerces estruturantes, mas também empreender práticas e experiências de arquivo que pelo menos possibilitem a salvaguarda da diversidade que se propõe a abarcar.

Para Denise Portinari em Queerizando o design, queerizar consiste em abrir os olhos do campo para as implicações éticas, estéticas e políticas de suas práticas na atualidade. Abertura que se dá a partir de um processo de tensionamento e sensibilização do campo sobre suas formas de atuação e seus escoamentos subjetivos, "abordando-o enquanto processo social de configuração do 
sensível compartilhado, do espaço comum" (PORTINARI, 2017, p. 2). Queerizar o design trata, portanto, de pôr foco em seus processos constitutivos e atribuir responsabilidades culturais e sociais, econômicas e políticas: expor o que se pretende esconder.

Para Portinari (2017), essa queerização passa por trazer à luz a atuação de designers na produção da normatividade, uma análise sobre as maneiras como se inserem nesse processo e suas implicações políticas. Problematizar a normatividade e potencializar a diferença, onde elas são produzidas: "nos dispositivos de saber e de poder, na performatividade dos discursos e das práticas, na materialização e partilha das (in)visibilidades - e nos seus pontos de fragmentação e fissura" (PORTINARI, 2017, p. 14).

É o que faz Adrian Forty, por exemplo, em Objetos de desejo (2007), quando analisa diferentes objetos de consumo e os discursos a eles atribuídos, em catálogos de venda postal norteamericanos na virada para o século XX. Seu objetivo era demonstrar certas categorias e a naturalização da marcação, via desenhos têxteis e de mobiliários, das diferenças entre homens e mulheres, crianças e adultos, ricos e pobres; demonstrando a atuação do Design como mecanismo de estruturação de lógicas binárias, reforçador de discursos de gênero.

O autor mostra como o design está politicamente envolvido na cultura material, ao responder aos contextos dos períodos nos quais está inserido, atentando, ainda para o quanto o design, na sua tarefa de conceber, projetar e dar forma, se incumbe de reforçar e perpetuar discursos normativos que predominam no tempo, e espaço, em que atua; e para além dos mesmos, tornandose, via arquivamento, documento de dado discurso em determinado período, servindo, em última instância, como prova material de maquinários normativos.

Jack Halberstam, por sua vez, em In a Queer Time and Place: Transgender Bodies, Subcultural Lives (2005), pondera que o desenho de meios para salvaguarda de memórias sexo e gênero dissidentes, já direcionando para nosso objeto principal neste texto, deve ser tratado não como um mero repositório, mas como um processo de memória coletiva aberto, que deve permitir acesso livre e irrestrito para outros olhares capazes de lidar com a complexidade das histórias neles presentes.

Halberstam (2005) fala da proposta de um bloco histórico, que tece alianças entre a academia e dissidências, e de como investigações universitárias têm um papel fundamental não somente na construção de memórias e arquivos queer, mas na circulação de suas complexidades. Tal apuro, segundo o autor, colabora para que a radicalidade dos trabalhos permaneçam nas mãos das "subculturas transviadas" (HALBERSTAM, 2005).

A partir dessa reflexão mais ampla, pretende-se enquadrar o objeto do presente texto sob uma perspectiva específica, pela qual perguntamo-nos, como, então, pensar numa práxis do design por meio de estratégias contra-normativas? É por meio do experimento de criação de uma plataforma digital para salvaguarda de memórias de ativismos sexo e gênero dissidentes que visamos aferir possibilidades. 


\section{Escritas da história e políticas de memória.}

No ano de 1500 , no que veio a ser submetido enquanto Brasil, era grande a liberdade nas práticas sexuais dos povos originários ${ }^{3}$. Com a invasão portuguesa, os colonizadores trazem consigo a ideia de pecado nefando, que envolve a condenação moral da sodomia (sexo anal) e de outras práticas como o travestismo, conforme evidenciam os registros da inquisição católica do santo ofício ${ }^{4}$. Assim como na Europa, a moral cristã chegava para ficar e ditar normas de comportamento no que tange gênero e práticas sexuais - monogamia, sexo somente para procriação, inferiorização da mulher, supremacia do falo, heterossexualidade compulsória etc.

Apesar das persistentes tentativas de controle através do imaginário de família tradicional brasileira judaico-cristã, corpos sexo e gênero dissidentes - travestismos, viadagens e outros 'desvios' - nunca deixaram de evidenciar-se, ainda que sejam violentamente combatidos até os dias de hoje. Isto se dá através de estratégias de sobrevivência de personalidades como Xica Manicongo ${ }^{5}$, considerada a primeira travesti brasileira em 1591, ou Madame Satã ${ }^{6}$, rainha da Lapa nos anos 1920, entre tantas outras, e as articulações políticas e ativistas iniciadas no final dos anos 1970 no Brasil, em grande medida influenciadas pela Revolta de Stonewall em Nova Iorque, em 1969, liderada por travestis negras insatisfeitas com as incursões violentas da polícia no bar que frequentavam.

Já no final da década de 1980, nos Estados Unidos, lésbicas e gays ativistas, descontentes com as políticas identitárias normativas que ainda trabalhavam dentro de um recorte assimilacionista (ser discreto para ser aceito), dedicaram-se a abrir frentes críticas de enfrentamento que denunciassem os mecanismos de produção de discursos e dispositivos regulatórios. A partir desse gesto de levante, setores da comunidade acadêmica e das organizações civis de ativismos iniciaram proposições queer (termo da língua inglesa que tem caráter pejorativo correspondente à estranho e a desajustado) - ferramentas políticas de enfrentamento às violências simbólicas, e físicas, sofridas por corpos dissidentes 'desencaixados' - bichas afeminadas, sapatões masculinas, pessoas transgêneres e travestis.

Movimentos ativistas como o ACT UP ${ }^{7}$, de insurgência pela atenção sanitária do estado norte americano diante da epidemia de AIDS, a qual se intensificou no final dos 1980, também colaboraram para a configuração do que hoje entendemos por estudos queer, sobretudo no que concerne à sua divulgação pública enquanto saber — edições do primeiro volume de História da

\footnotetext{
${ }^{3}$ MOTT, Luiz. Etno-história da homossexualidade na América Latina https://edisciplinas.usp.br/pluginfile.php/4250459/mod_resource/content/1/04.-Luiz_Mott.pdf 4 ibid

5 JESUS, Jaqueline Gomes de. Xica Manicongo: a transgeneridade toma a palavra. https://www.epublicacoes.uerj.br/index.php/re-doc/article/view/41817/0

${ }^{6}$ https://revistahibrida.com.br/revista/edicao-3/inspiracao-madame-sata-a-bicha-preta-mais-temida-dobrasil/

7 A sigla ACT UP significa AIDS Coalition to Unleash Power ou, em tradução minha, Coalizão para Libertação do Poder na luta contra a AIDS.
} 
Sexualidade I: A Vontade de Saber de Michel Foucault eram levadas nos bolsos de membros do ACT UP.

O trabalho do filósofo, uma das bases para as articulações dessa teoria, foi, em grande medida, dedicado a uma criteriosa análise das estruturas formativas das sociedades disciplinares. A partir da disciplina dos corpos e das regulações das populações, Foucault (1998) descreve um incessante investimento sobre a vida, compreendidos como discursos - o teremos em mente ao refletir o desenho de arquivos sexo e gênero dissidentes. Foucault investigou como, entre os séculos XVIII e XIX, nas sociedades ocidentais, os discursos públicos sobre o sexo se intensificam, principiando uma forte verbalização e associação à determinada noção de sexualidade, forjando-se lentamente, entre outras figuras.

O personagem do sujeito homossexual, agora dotado de substância psicológica própria a partir de um processo de patologização descrita como desvio. Já não é apenas mais a prática da sodomia (condenação do sexo anal) que está em jogo, mas, sim, toda uma constituição do indivíduo a partir do desejo, definidoras de um lugar de desvio necessário para a construção do que seria a representação de um suposto 'normal', ou seja, a figura do heterossexual; um sujeito ajustado, considerado apropriado às lógicas de produção capitalistas: primordialmente branco, sadio, de sexualidade também dita sadia, não excessiva, que garanta energia suficiente para a força de trabalho (FOUCAULT, 1998).

É assim que todo um aparato se configura e produz por meio de discursos medicalizantes, judiciais e religiosos que dão conta de perpetuar esse perfil do "homem" ideal e de tornar abjetos os "vagabundos", não encaixados nessas premissas. Cria-se, portanto, relações de poder que estabelecem policiamentos normativos que intentam a regulação, condenação e invisibilização dos corpos dotados de patologia - gays, lésbicas, pessoas trans e travestis. As consequências políticas, sociais e econômicas dessa trama complexa de produção discursiva se tornam evidentes, por exemplo, quando em pleno ano de 2021, a homossexualidade segue sendo uma prática ilegal (condenada por lei) em 69 países do mundo ${ }^{8}$.

Na mesma década em que o ACT UP atuava, final dos anos 1980, a filósofa Judith Butler também se consolidou como um dos bastiões da problematização de binarismos de gênero e sexo, notadamente com a obra Problemas de Gênero, e outras que seguiram, nas quais defende gênero como um constructo social e performativo. Butler (2003) propõe questionar essa suposta ordem que demanda uma coerência entre sexo, gênero e desejo, como premissa sede afirmação cisheteronormativa. Para Butler (2003), o gênero é performativo, ou seja, é tornado inteligível através de gestos, posturas, convenções sociais, nomes, vestimentas, cortes de cabelo, que são performados de maneira a sermos submetidos e também submetermos nós mesmos, e os nossos corpos, a uma inteligibilidade binária: homem - mulher.

Assim, o que se entende por cisheteronormatividade se refere a um conjunto de práticas e dispositivos jurídicos, médicos e culturais que trabalham para que os comportamentos sejam ditados por normas sociais a partir da noção dominante de heterossexualidade. A própria

\footnotetext{
${ }^{8}$ Ver https://www.bbc.com/portuguese/internacional-57641679
} 
homossexualidade seria uma definição criada a partir desse conjunto de normas para designar os indivíduos considerados anormais e desencaixados. Ser uma pessoa cisgênero significa que eu me identifico com o gênero que me foi atribuído ao nascer. Muitas outras pessoas não se sentem confortáveis com o gênero que lhes foi designado, ou rejeitam essa definição, e são classificadas como transgêneres ou travestis.

Ora, se a cisheteronorma lança mão de práticas e discursos que objetivam tornar as pessoas inteligíveis a partir de uma chave imposta de entendimento, muitas outras pessoas, que rejeitam ou não se entendem dentro dessa chave, emitem outros códigos, outros desejos sociais politicamente discordantes. Para garantir suas sobrevivências, faz-se necessário colocar em prática insurreições críticas para dar a ver estas tentativas de ordenamento opressivo e criar espaços de liberdade para o desenho do próprio corpo, de seus modos de vida, e sobrevivência, que desestruturam a ordem sexo-gênero-política estabelecida.

Nessa linha, a pesquisadora Guacira Lopes Louro, uma das precursoras dos estudos queer na educação, no Brasil dos anos 2000, entende que, mais do que buscar uma nova identidade, as práticas queer pretendem se afirmar na diferença, em um movimento contrário a assimilação, o que torna suas proposições mais desestabilizadoras da ordem (LOURO, 2004).

Queerizar (PORTINARI, 2017) trata-se, portanto, de engendrar meios para desorganizar práticas normativas e articular outros modos de subjetivação. O filósofo Paul Preciado, em seu Manifesto Contrassexual (2015), defende a ideia de contrassexualidade como uma forma de resistência à produção disciplinante das sexualidades em nossas sociedades, permissivas e falsamente tolerantes ao defender que não se trata de uma luta contra a proibição, mas, sim, de operar a partir da contraprodutividade; ou seja, a produção de formas de saber, fazer e prazer, alternativas às sexualidades modernas das sociedades ocidentais de cultura de massas.

A partir desta breve localização quanto à nossa aproximação com os estudos queer, seguiremos ao desenho de arquivos como ativismo político, à luz de entendimentos proporcionados por aberturas teóricas como as de Michel Foucault e Achille Mbembe, cujos olhares ampliam horizontes que auxiliam a implicar politicamente o Design, sobretudo quanto ao seu papel na construção e, também, desconstrução de sistemas de controle de informação. Tomamos como ponto de partida o entendimento de repositórios documentais como memória coletiva, coleções de evidências e classificações do passado servindo como subsídios, no presente, para a conformação de discursos, histórias e ficções que constituem os saberes.

\section{Práticas de discurso público: arquivos transviados.}

Em Arqueologia do saber, Michel Foucault (2008) investigou, através do método de trabalho arqueológico, sistemas, dinâmicas e mecanismos que fazem de práticas discursivas, regras sociais. O autor define discursos como conjuntos de enunciados que, ao longo dos tempos e espaços, conformam áreas autônomas, porém interconectadas; as disciplinas (medicina, direito, antropologia, psicologia, museologia, etc.). Através desta arqueologia, o autor apontou caminhos 
para a compreensão sobre como os saberes (construção de verdades) emergem das relações discursivas, nas quais têm lugar as unificações e rupturas às condições de aparecimento, encadeamento e desaparecimento, entre outras formas de forjar a história.

Em suas investigações, Foucault (2008) não trata de julgar e interpretar o teor de discursos em si, mas de estabelecer um olhar sobre enunciados, este conjunto de vestígios que tornam um registro discursivamente relevante. Esse olhar, definido como arqueologia, não pretende buscar começo ou fim, ou atrelar seus achados a uma cronologia, mas interrogar o que já foi dito, as "coisas ditas" no nível de sua existência: "A arqueologia descreve os discursos como práticas especificadas no elemento do arquivo" (FOUCAULT, 2008, p. 149).

É a partir dessas formulações que propõem determinada forma de olhar que este teórico inclui o arquivo em sua arqueologia dos saberes, como um sistema de enunciados que tem acontecimentos de um lado, e coisas (estruturas) de outro; elucidando como nas tecnologias das práticas discursivas se encontram em atuação sistemas que determinam enunciados (regras que tornam uma expressão discursiva significativa), como também acontecimentos (produção de verdade).

Estes se dariam a partir de condições do que este autor chama de domínio de aparecimento e arcabouço que suporta acontecimentos: "o arquivo é, de início, a lei do que pode ser dito, o sistema que rege o aparecimento dos enunciados como acontecimentos singulares" (FOUCAULT, 2008, p. 147). Esses dois elementos - acontecimentos e coisas - dão forma ao arquivo, e neles se instauram relações de poder que logo darão um sentido ao discurso.

Já Achilles Mbembe, em O Poder dos Arquivos e seus Limites (2002), afirma que o arquivo é produto de um julgamento, o resultado de práticas de um poder e uma competência específicos; julgamento que resulta na conservação de certas evidências, enquanto outras são rejeitadas. $O$ arquivo é, segundo o pensador, discriminatório em sua essência, o que leva a conferir privilégios a certos discursos e atribuir status hierárquico de "não arquivável' a outros: “O arquivo não é um dado, é um status" (MBEMBE, 2002, p. 20).

Status que garante visibilidade, uma posição na hierarquia, e, principalmente, status de prova. Prova de que vida existe, algo aconteceu, e, portanto, matéria para que discursos sejam transformados em verdades. O destino do arquivo está localizado fora da sua própria materialidade ao se tornar parte de uma história com a qual colaborou.

Se o arquivo é inseparável de um jogo de relações de poder, podemos afirmar, portanto, que o arquivo não é isento, tampouco neutro. Na sua origem, o arquivo é constitutivo do discurso, logo, politicamente responsável pelo que comunica. Mais do que ser um repositório do que foi proferido em discurso, e para além de um recurso que garante a permanência do meio do discurso, é o arquivo que faz o trabalho de diferenciação dos discursos, em toda a sua multiplicidade, e decide sua permanência no tempo.

Tampouco é isenta, portanto, a estrutura que sustenta, que garante presença e acesso, proteção e circulação, às memórias documentais, da feita que as memórias arquivadas, que são combustível para a escrita da história, estão diretamente ligadas às condições materiais e meios tecnológicos 
utilizados num dado momento; o que entendemos ser, pois, uma questão política também do Design.

O Design, campo em estruturação conceitual quanto às suas implicações culturais, sociais e políticas e, portanto, profícuo para ser analisado no que concerne às suas intersecções, tem expandido sua episteme por meio da elucidação dos processos discursivos imbricados no fazer design. Para tal, inclinamo-nos a pensar o design como técnica que sugere caminhos para dar forma e propor meios de distribuição da informação - algo que "in+forma" (CARDOSO, 2016), ou seja, que dá forma a algo: vaso comunicante.

Refletir acerca da constituição das estruturas dos arquivos que salvaguardam práticas sexo e gênero dissidentes, por conseguinte, é uma também maneira de investigar a memória social dos objetos técnicos, enquanto método de trabalho em pesquisa nas ciências humanas digitais, (tendo em vista a arqueologia dos saberes; e, em mente, a das mídias). É analisando como essas formas materializam-se que almejamos identificar que critérios e condições sociopolíticas e tecnocientíficas capazes de erigir estas engenharias: quem tem o privilégio de arquivo?

A responsabilidade política do campo do Design, entendido aqui como dispositivo gerador de estruturas e procedimentos de sustentação da arquitetura de informação que dão forma e sentido aos bancos de dados. O Design visibiliza, o Design invisibiliza; logo, trata-se de um agente tanto atuante na produção e na propagação de discursos, quanto em sua fragmentação e dispersão, impetrando práticas políticas ao definir os alicerces mnemônicos pelos quais os registros serão providos de sustentação, por quem serão salvaguardados, e por quanto tempo (em tempos de encurtada obsolescência programada): vozes silenciadas, mortes anunciadas.

Marshall McLuhan, profícuo teórico dos meios canadense, contribui para a compreensão dos fenômenos informacionais e comunicacionais pelos quais as sociedades tecnocientíficas têm se reconfigurado estruturalmente, sobretudo desde a Revolução Industrial, afirmando que a forma com que a mensagem é veiculada é tão importante quanto o teor transmitido - isto é, seu meio "os suportes são determinantes na mensagem: os conteúdos modificam-se em função dos meios que os veiculam. O meio é a mensagem porque é quem modela a forma, controla a escala, das associações e trabalho humanos" (McLUHAN, 1994, p. 12).

Essa abordagem crítica da interconexão entre a cultura de massas e os meios de comunicação encontra ainda matérias de investigação na formação do campo acadêmico do desenho industrial, após o qual torna-se imperativo pensar também o papel do designer como agente político na tanto na enunciação de discursos quanto na reflexão sobre os mesmos.

O sociólogo espanhol Manuel Castells, em consonância com este pensamento, atualizando-o para a análise de seu contexto no século XXI, defende, em $O$ Poder da Comunicação (2009), que qualquer possibilidade de mudança social deve passar por um processo de reprogramação das redes de comunicação, as quais constituem o ambiente para o processamento imagético e simbólico de informação em nossas vidas.

Desde a instauração de uma sociedade de redes (CASTELLS, 2009), alicerçada na cultura digital globalizada através das tecnologias de comunicação e informação, na qual o papel do 
design é, literalmente, estruturante, evidencia-se a necessidade do campo do Design - enquanto ciência não somente aplicada, mas também responsável politicamente por sua atuação - localizar os saberes que gera e gerencia: se até aqui procuramos tensionar o campo do design, torna-se imperativo (como na abordagem de Donna Haraway trazida ao princípio deste texto) pensar também o papel do designer como agente político no desenho de meios e processos de enunciação, que além de intermediar discursos, também projeta seus sistemas.

\section{Tropicuir.org - espaço e tempo para autorrepresentação.}

Como corpus de análise propomos o estudo de práticas de arquivamento que permeiam as práticas projetuais em operação na plataforma tropicuir.org, e que pensamos reunir condições de configurar-se como subsídio para nosso objetivo de refletir sobre estratégias para uma queerização da atuação de designers, situada no projeto da experiência do usuário em uma arquitetura da informação que salvaguarda memória digital via redes de computadores.

Instituir um espaço de construção de memória coletiva contra-normativo passaria pela necessidade de garantir autonomia na experiência da interface da salvaguarda. Passaria também pela configuração de um espaço de liberdade que garanta a visibilidade de práticas rejeitadas ou censuradas por outros espaços cibernéticos corporativos e institucionais.

A necessidade de um espaço seguro e independente nos levou a optar pela contratação de serviço de hospedagem e o manejo via plataforma auto-gestada, garantindo que o repositório de dados se mantenha sob nossa tutela, prevenindo que nos tornemos reféns de plataformas corporativas ditas 'gratuitas', que tomam para si o direito sobre os conteúdos.

Exercício para desprender-se da ideia de armazenamento estanque para imaginar um espaço de transmissão permanente. Não se trata de abandonar a ideia de salvaguarda, mas, sim, de construir meios de guarda que se estruturam através do compartilhamento, como dinâmicas de transmissão de forças entre vasos comunicantes.

A obsolescência programada e a precariedade da manutenção dos objetos técnicos em funcionamento enquanto meios de salvaguarda de memórias coloca, de antemão, um desafio sobre como habitar esses lugares a partir de uma perspectiva crítica queer. Uma das preocupações na concepção dessa plataforma digital reside na escolha dos meios tecnológicos.

Quais tecnologias resistem ao tempo e à evolução das estruturas sem que sejam dinâmicas que invisibilizam as próprias categorizações? Qual nível de flexibilidade deve ser mantido para que a plataforma se adapte a novos cenários ao longo do processo? Qual o nível de adaptabilidade e segurança necessário para acolher registros tão díspares?

Wolfgang Ernst (2016) em Des-historicizando radicalmente o arquivo, sugere que o primeiro passo nessa jornada deve ser nos desfazermos da ideia de arquivo como um repositório coerente fornecedor de memórias, tendo em mente uma multiplicidade de camadas temporais conectadas. 
A ideia de um arquivo em movimento é paradoxal, pois o arquivo é tradicionalmente aquilo que depõe com o tempo, que interrompe o movimento (ERNST, 2016). Mas ao ser disponível eletronicamente, o arquivo é desprovido de sua forma tradicional, e suas formas imperfeitas se convertem em arquiteturas de informação para engenharia das comunicações.

Para Ernst (2016), o novo arquivo é radicalmente temporalizado, mas não linear, multidirecional; é efêmero, correspondendo a uma cultura dinâmica, pois responde a uma diversidade de práticas concomitantes, e interdependentes, de práticas de memória de corpos dissidentes por meio de objetos técnicos.

Buscamos, portanto, juntar fragmentos de memórias apagadas e interrompidas (a linearidade é uma invenção moderna, e a continuidade não é uma possibilidade para muitas de nós); rastros que minimamente localizados no tempo, informam uma marcação material e promovem encontros de diferentes temporalidades num só espaço.

Em uma visita aos arquivos da Amateur Archivist (2015), deparamo-nos com a seguinte pergunta: "Como configurar um arquivo, um quadro de classificação, uma ferramenta de recuperação, índices, catálogos, de materiais que procedem de pessoas que desafiam a taxonomia a cada dia?". Além disso, Derrida ainda declara que não há arquivamento sem título, sem nome e por isso sem lei que dita sua legitimação, que o classifica e o hierarquiza: "sem ordem e sem ordem, no duplo sentido desta palavra" (DERRIDA, 2001 p. 56).

Deparamo-nos, nós também, com um desafio no processo de classificação de obras, experiências e vivências tão múltiplas, vórtex de indagações: como reapropriar-nos taticamente de metodologias arquivísticas - como classificar os desclassificados?

\section{Zona de transmissão e formas de contágio.}

Sob uma perspectiva queer, que objetiva extrapolar o gesto de atribuir identidades, categorias, padronizações... que tanto serviram para patologizar e subalternizar muitos corpos, a estratégia adotada foi a de não tratar classificações segundo critérios médicos ou antropo-biométricos: ao contrario, a partir de afirmação e ressignificação de insultos, e da ausência de censura no que tange sua utilização; nesse sentido, por exemplo, propomos utilizar bicha, ou bixa, no lugar de gay; sapatão, ou fancha, em lugar de lésbica.

Buscamos ainda alimentar-nos de fontes não usuais à heteronorma de categorização de dados, como a língua pajubá - derivada do iorubá ou nagô e muito utilizada pelas travestis como código secreto durante a ditadura militar no Brasil - cada vez mais em uso: termos como acuendar, amapô, fechação, fundamento, acué, homossexuellen, sapa, vuduzar, bafo... fazem-se não somente presentes; mas também, e sobretudo, estruturante na catalogação.

A digitalização da cultura nas sociedades em rede permite tanto a colaboração comunitária por meio da doação de registros documentais, via suportes digitais, para a conformação de repositórios arquivísticos, quanto a cooperação coletiva na escrita de histórias do tempo presente: 
a internet enquanto papiro contemporâneo, capaz de fomentar a auto-representação também de grupos de devir minoritário silenciados pelos sistemas de controle discursivo.

Nestes contextos, termos classificatórios, que caracterizam grupos ou indivíduos, surgem a partir das categorizações propostas por cada uma das agentes participantes na plataforma, que dão corpo aos conjuntos e letra às palavras-chaves, tornando-se historiadores de si mesmos, ao documentar sua realidade segundo critérios definidos a posteriori.

Por se tratar de um arquivo consensual, grande parte dos registros publicados na plataforma foram compilados através de escutas e trocas entre os agentes, garantindo que as informações arquivísticas, registros imagéticos e produções textuais nela registrados estivessem em sintonia com seus desejos de autorrepresentação e visibilidade, bem como de invisibilidade, muitas vezes necessário para garantir segurança e integridade física.

Desenhar meios de autorrepresentação como proposta para escapar do que é contado, para ir na direção do corpo contador de suas próprias histórias: feito objeto e abjeto, se trata de nos tornarmos sujeitos da nossa memória coletiva - afirma a teórica chicana lésbico-feminista Gloria Anzaldúa (2000, p. 232): "Escrevo para registrar o que os outros apagam quando falo, para reescrever as histórias mal escritas sobre mim, sobre você [...] escreverei sobre o não dito, sem me importar com o suspiro de ultraje do censor e da audiência".

As estratégias supracitadas propõem, em certa medida, um retorno - não saudosista - às práticas de uma internet de acesso livre, como proteção às normas morais e censuras de redes sociais hegemônicas e fechadas em si mesmas. Nesses portais corporativos fechados em si, entregamos nossos registros de memória para tornar-se propriedade privada de modo alheio ao nosso controle, podendo simplesmente ser vendidos, distorcidos ou apagados.

A rede social Orkut, por exemplo, desapareceu por completo. O mesmo aconteceu com o Geocities, um dos primeiros portais a abrigar páginas de usuários. Da maneira como são construídas, redes sociais baseiam-se em recompensas emocionais de curta duração, que demandam novos estímulos de forma continuada: auto-fagocitoses imagéticas simultâneas. Sob esta mecânica mnemônica, nossa memória coletiva torna-se inerentemente volátil e, mais do que nunca, nossas escritas da história se subjugam às políticas de esquecimento.

Castells (2009) defende que, na sociedade da informação, qualquer possibilidade de mudança social deve passar por um processo de reprogramação das redes de comunicação, que constituem o ambiente para o processamento simbólico em nossas vidas. Segundo o autor, outras formas de configuração, que conectem mentes por meio de seus dispositivos comunicacionais, são essenciais para o desenvolvimento de novos conteúdos, capazes de representar formas de existência que extrapolam as normatividades difundidas midiaticamente.

Quanto mais autonomia a plataforma puder garantir aos sujeitos comunicantes, maiores serão as possibilidades de comunicação de mensagens que perturbem discursos e valores dominantes (Castells, 2009). Em tropicuir.org, empreendemos tentativa semelhante de coletivização das dinâmicas mnêmicas, pretendendo agenciar práticas arquivísticas de auto-representação, 
conectando, assim, temporalidades múltiplas, com o intuito de possibilitar a documentação autônoma de fontes históricas de ativismos sexo e gênero dissidentes.

Os rastros que deixamos e suas respectivas efemeridades, sinais intermitentes, são lugares de potência transviada profundamente presentes, posto sua precariedade e potencialidade. São movimentos mapeados que ganham potência na medida em que tomamos consciência do que está em jogo: falas e escutas, por entre rastros humanos deixados como vestígios cibernéticos; corporeidades em combinações infinitas.

Este reporte é também um convite à reflexão acerca do campo do Design enquanto saber imbricado nas políticas de memória social por meio de sua atuação no desenvolvimento de tecnologias de informação e comunicação, que visa amplificar sobretudo o debate interno na área; através, por exemplo, da realização de experimentações coletivas como a deste repositório mnemônico para salvaguarda digital, que visa contribuir para que ativismos políticos e práticas artísticas de pessoas sexo e gênero dissidentes tenham espaço para existir, e resistir ao tempo.

\section{Referências}

ANZALDÚA, Gloria. Falando em línguas: uma carta para as mulheres escritoras do terceiro mundo. Revista Estudos Feministas, v. 8, n.1, p. 229-236, 2000.

BENTO, Berenice. Queer o quê? Ativismo e estudos transviados. Entrevista. Revista Cult, ed. 193, agosto 2014

BUTLER, Judith. Problemas de gênero: feminismo e subversão da identidade. Rio de janeiro: Civilização Brasileira, 2003. 238 p.

CARDOSO, Rafael. Design para um mundo complexo. São Paulo: Ubu Editora, 2016. 264 p.

CASTELLS, Manuel. Communication Power. Oxford: Oxford University Press, 2009. 571 p.

DERRIDA, Jacques. Mal de Arquivo: uma impressão freudiana. Rio de Janeiro: Relume Dumará, 2001. 133 p.

ERNST, Wolfgang. Radically De-historicising the archive: Decolonising archival memory from the supremacy of historical discourse. IN: Decolonising the Archives. Madrid: L'Internationale Online, 2016. p 9-16.

FOUCAULT, Michel. A Arqueologia do Saber. Rio de Janeiro: Forense Universitária, 2008. $236 \mathrm{p}$.

FOUCAULT, Michel. História da Sexualidade vol 1 - A vontade de saber. Rio de Janeiro: Edições Graal, 1998. 176 p.

FORTY, Adrian. Objetos de desejo. São Paulo: Cosac \& Naify, 2007. 352 p.

HALBERSTAM, Jack. In a Queer Time and Place: Transgender Bodies, Subcultural Lives. Nova Iorque: New York University Press, 2005. 247 p.

HARAWAY, Donna. Saberes localizados: a questão da ciência para o feminismo e o privilégio da perspectiva parcial. Cadernos Pagu, n. 5, p. 7-41, 1 jan. 1995.

LOURO, Guacira Lopes. Um corpo estranho: ensaios sobre sexualidade e a teoria queer. Belo Horizonte: Autêntica, 2004. 96 p. 
MBEMBE, Achille. The Power of the Archive and its Limits. IN: HAMILTON, Carolyn, HARRIS, Verne, PICKOVER, Michele, REID, Graeme, SALEH, Razia, Taylor, J. (Eds.) Refiguring the archive. Dordrecht: Springer, 2002. 368p. p. 19-26

MCLUHAN, Marshall; LAPHAM Lewis. Understanding Media - The Extensions of Man. Boston: MIT Press, 1994. 398 p.

PORTINARI, Denise. Queerizar o Design. Revista Arcos Design, Rio de Janeiro, Edição especial Seminário Design.Com, v.10, n.1, p. 1-19, Outubro 2017

PRECIADO, Paul B. Manifesto Contrassexual. São Paulo: N-1 Editora, 2015. 224 p.

\section{Sobre os autores}

\section{Guilherme Altmayer}

Professor adjunto do Departamento de Integração Cultural da Escola Superior de Desenho Industrial na Universidade Estadual do Rio de Janeiro. Doutor e mestre em Design pela linha de pesquisa Comunicação Cultura e Artes do Programa de Pós-graduação em Design da Pontifícia Universidade Católica do Rio de Janeiro.

ORCID.

\section{Leno Veras}

Doutorando em Comunicação e Cultura pela linha de pesquisa Tecnologias de Comunicação e Estéticas no Programa de Pós-Graduação em Comunicação da Universidade Federal do Rio de Janeiro. Mestre em Comunicação e Sociedade pelo eixo Estética e Narrativas da linha Imagem e Som no Pós-graduação em Comunicação da Universidade de Brasília.

ORCID. 